\title{
Del leer, nace el saber: la lectura en el refranero
}

\author{
Elena GUARDIOLA, Josep-E BAÑOS
}

\section{From reading, knowledge is born: reading in Spanish sayings}

\author{
Departamento de Ciencias Experimentales y de la Salud. Universitat Pompeu Fabra. Barcelona (España). \\ Autor para correspondencia: Josep E Baños. Correo electrónico: josepeladi.banos@upf.edu \\ Recibido el 11 de marzo de 2019; aceptado el 14 de marzo de 2019.
}

Cómo citar este artículo: Guardiola E, Baños JE. Del leer, nace el saber: la lectura en el refranero. Rev Med Cine [Internet] 2019;15(2):61-2. DOI: http://dx.doi.org/10.14201/rmc20191526162

Decíamos en un Editoria/ ${ }^{1}$ anterior que el refranero tiene refranes para todo. Nos centrábamos entonces en los que dedica al libro y reservábamos esta nueva ocasión para hacer un paseo por los que se refieren a todo aquello que tiene que ver con leer y con la lectura.

Vimos ya entonces que, como no podía ser de otra manera, algunos refranes se refieren tanto al libro como a la lectura. "Libro cuya lectura no te mejore, quizá te empeore", "Libro sin lectura, no da sabiduría" o "Ni todos los que tienen libros son lectores ni todos los que tienen escopeta son cazadores" nos sitúan en distintos escenarios; pero no son éstos los únicos que encontramos, como lo demuestran: "Vino viejo para beber, sarmientos para arder y buen libro para leer" y "Si a tu vecino quieres conocer, averigua qué libros suele leer".

Los refranes nos indican que leer es imprescindible para aprender: "Mucho leer y bien entender, el mejor camino para aprender" y también "Mucho leer y bien entender, el mejor camino para saber" porque "Leyendo y leyendo va el niño aprendiendo, y sabio se haciendo" y "Leyendo y escuchando, el necio se hace sabio". Está bien claro que "Del leer nace (o sale) el saber", que "Para saber, has de leer" y que "Quien poco lee, poco aprende".

Pero este es sólo el primer paso, que nos ayudará a obrar correctamente, "Leer para saber, y para obrar, recapacitar" y "Quien leyere, lea para saber; y quien supiere, sepa para obrar", y saldremos beneficiados: "Quien lee y escribe no pide pan". Y si además se puede viajar, mucho mejor "El que lee mucho y anda mucho, ve mucho y sabe mucho" ya que la instrucción más sólida es la que se adquiere con los viajes y en la lectura.

Y en cuanto a cuál es la mejor época de la vida para dedicarse a la lectura parece que "Las letras y la virtud, en mocedad y en senectud", pero donde hay que hacerlo siempre es en la escuela ya que "El que mea y no pee, es como el que va a la escuela y no lee".

Parece obvio que las lecturas influyen en las personas: "Dime lo que lees y te diré como piensas" porque "Según lo que leas serán tus ideas" y "Tal eres cuales son los libros que lees".

Hay que leer prestando atención y sin prisas, "Mal se entera quien lee de priesa"; es lo mismo que hay que hacer al comer "Leer y comer, despacio lo has de hacer", pero no se puede hacer ambas cosas simultáneamente: "Leer y comer, no puede ser".

Además, nos dice el refranero que es imprescindible entender y aprender cuando se lee. No hay que olvidar que "Leer y no entender, es como cazar y no coger", que "Quien lee y no aprende, caza y no prende" y que "Leer sin fruto sacar, es mascar y no tragar". Pero si, a pesar de todo, no se tiene éxito con la lectura, acaba recomendando "Si lees mucho y mal te enteras, valdría más que no leyeras".

E insiste, una y otra vez, en que hay que entender lo que se lee porque "Leer sin entender, no es leer" y si así lo hacemos, perdemos el tiempo: "Leer sin hacerse 
cargo de lo leído, tiempo perdido" o lo que es lo mismo "No entender lo que se ha leído, tiempo perdido". Además "Quien lee y no entiende, nada aprende" porque "Leer y no entender, es mirar y no ver" y "Leer y no entender, es querer y no poder".

Pero no es adecuado leer en cualquier momento del día. "Después de comer, ni un sobre leer" -y también sus distintas variantes "Después de comer, ni un sobre escrito (o sobrescrito) leer", "Después de comer, ni un sobre has de leer" o "Después de comer, ni una letra leer"- advierte que resulta perjudicial realizar un esfuerzo mental inmediatamente después de haber comido.

Los refranes señalan que en muchas actividades hay que tomar precauciones y ser prudente. Nos dicen "Ni firmes carta que no leas ni bebas agua que no veas" y también, de forma similar, "Ni bebas sin ver, ni firmes sin leer" o "Ni comer sin beber, ni firmar sin leer" y comparándolo con actos de mayor trascendencia, "Ni cases sin ver, ni firmes sin leer". Y si no se hace así, afirma que "Firmar sin leer, sólo un necio lo puede hacer".

"Quien sabe leer y escribir, a todas partes puede ir", pero, sin duda, lo que hay que saber leer es siempre la propia escritura. Según el refranero "Asno es de natura, quien no sabe leer su escritura", "Burro es, y no hombre, quien leer no sabe sus propios renglones" y "Burro llamo yo a quien no sabe leer lo que escribió".

La lectura tiene también propiedades terapéuticas y así se reconocen: "La buena lectura distrae, enseña y cura". Asimismo, mejora el estado de ánimo porque "La buena lectura, alivia la tristura" y "Contra tristura, buena lectura" y se recomienda "Espíritu enfermo, busque en la lectura su remedio" para que no ocurra que "Ocio sin lectura, vida en sepultura".

Y aunque en tiempos pretéritos fue bien conocido que "La letra con sangre entra", el propio refranero añadió después "La letra con sangre entra, pero con dulzura y amor se enseña mejor".

En los refranes hallamos también la crítica al que pretende ser sabio y dar lecciones cuando en realidad carece de conocimientos en la materia: "El maestro Ciruela, que no sabía leer y puso escuela". En este refrán figurado y familiar se censura al que habla magistralmente de cosas que no entiende; tiene también diversas variantes como "El maestro Ciruela, que no sabe leer y pone escuela", "El maestro de Algodor, que no sabía leer y daba lección" o "El maestro Quiñones, que no sabía leer y daba lecciones".

Pero, en cualquier caso, la lectura forma siempre parte de lo más preciado: "Es un tesoro tener libros viejos para leer, viejos vinos para beber, vieja leña para calentar y viejos amigos para recordar" o, de forma similar, "Es un tesoro tener leña seca para quemar, caballo viejo para cabalgar, vino añejo para beber, amigos ancianos para conversar y libros antiguos para leer".

\section{Referencia}

1. Guardiola E, Baños JE. Libro cerrado, no saca letrado: lo que los refranes nos enseñan. Rev Med Cine. 2018;14(4):225-6.

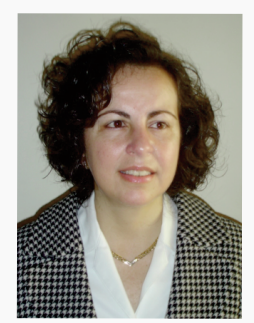

Elena Guardiola es doctora en Medicina. Investigadora asociada en la Facultad de Ciencias de la Salud y de la Vida de la UPF desde 2007, se ha especializado en información, documentación y redacción científica, áreas en las que ha impartido numerosos cursos. Su interés por la relación entre la medicina y la literatura se ha plasmado en la participación en varios proyectos así como en la publicación de diversos trabajos. 